\title{
MARÍA DE LA HOZ: \\ TONO Y MIHURA EN LAS TRINCHERAS
}

Julián Moreiro

IES Ciudad de los poetas (Madrid)

Para el grupo de humoristas que alcanzó la madurez mediada la década de los veinte, y que podríamos denominar «Generación de Gutiérrez» por haber dejado casi todos ellos una muestra acabada de su maestría en las páginas de aquella revista madrileña dirigida por $\mathrm{K}$-Hito, la guerra civil supuso, como para tantos otros creadores, una experiencia traumática, por más que la vivieran con una cierta distancia en la mayoría de los casos. $\mathrm{Y}$ ha de tenerse en cuenta la repercusión del drama en sus vidas y en sus trayectorias profesionales pues, en caso contrario, la historia del humor durante el primer franquismo se entenderá mal.

Edgar Neville, Jardiel Poncela, López Rubio, Tono, Mihura y Antoniorrobles, los más sobresalientes herederos de Ramón Gómez de la Serna, habían renovado el concepto del humor con sus colaboraciones en las audaces revistas aparecidas durante la década de los veinte; además, los cuatro primeros, habían vivido en Hollywood una experiencia insólita (de la que no parece que supieran sacar mucho partido) como adaptadores de diálogos. Sucedía eso en los años treinta, mientras la II República iniciaba su azarosa existencia. Con la excepción de Antoniorrobles, que asumió su compromiso y vivió tras la contienda largos años en el exilio, ninguno de los citados mostró entusiasmo alguno por la nueva situación política española, si bien optaron por un prudente retraimiento acorde con su propensión al abstencionismo como norma de vida; cabe señalar, no obstante, el caso excepcional de Edgar Neville, que militó en Izquierda Republicana 
hasta septiembre de 1936 y hubo luego de hacer méritos extraordinarios y reinterpretar su pasado (Ríos Carratalá 2005b:102-103).

Cuando comenzó la contienda, unos y otros procuraron colocarse a cubierto en la zona franquista, encontraron un cómodo rincón en la retaguardia y pusieron su talento al servicio de la causa. Su elección tenía que ver con factores culturales y con su adscripción de clase, aunque no siempre verbalizaron sus razones, circunstancia a la que, seguramente, ha de atribuirse el escaso eco que el asunto ha encontrado en la crítica. Pero no faltan miradas más atentas a la suerte del humor y de los humoristas en aquellas trágicas circunstancias:

Sin ningún sentido peyorativo, podemos hablar de unos «señoritos de la república», que renegaron de la misma cuando vieron peligrar su condición de «señoritos». A pesar de que la situación social de Miguel Mihura no es equiparable a la de Jardiel Poncela o Edgar Neville, la adhesión de los tres a la sublevación es un intento de preservar unos privilegios, no solo económicos, incompatibles con la toma de poder por parte de «la chusma» objeto de sus sátiras. Y puestos a elegir entre dichos privilegios y la libertad, no dudaron (Ríos Carratalá, 2005a: 20).

Ese juicio, que parece irrefutable, es compatible con las tibias explicaciones aportadas por los interesados para justificar su conducta. Cuando Miguel Mihura habla de su decisión de abandonar el Madrid republicano, lo hace con un cierto tono frívolo como en otra ocasión he comentado (Moreiro, 2004: 175-176); y solventa de un plumazo - que disimula, pero no oculta, una motivación más profunda- la cuestión de las dos Españas: «Comprendí que la zona roja no nos iba ni a España ni a nosotros, los españoles. Y entonces, yo me dije: «Estos señores que se vayan a hacer puñetas. No me interesan y me voy con los otros»»». Simplificar la realidad con ironía es un recurso que, entre otras cosas, permite autojustificarse y ponerse a salvo; pero se trata de una falsa impresión, pues la realidad no puede dejar de ser como es: irse con los otros para poner a su servicio la pluma y el talento era una forma de acudir a las trincheras. Y los humoristas lo hicieron a veces por convencimiento, a veces por simpatía y en ocasiones por inercia.

\section{Un trabajo de propaganda en colaboración}

A finales de enero de 1937, Miguel Mihura consiguió salir de Madrid con su madre. Dos semanas después de llegar a Valencia, se les presentó la ocasión de ocupar dos puestos libres en un avión que volaba a Toulouse con brigadistas franceses heridos en combate. Desde la ciudad francesa, 
Mihura entró en contacto con Tono, que estaba en París desde antes del inicio de la guerra, y su amigo le ofreció una casa que tenía en Hendaya. El 23 de febrero, madre e hijo cruzaron la frontera de Irún y se reunieron en San Sebastián con Jerónimo, el hermano mayor de Miguel, que había llegado meses antes. Por su parte, Tono dejó las orillas del Sena y se instaló también en la privilegiada capital de la retaguardia franquista (donde Mihura confesaría más tarde que había vivido «como un marqués»), un reducto de paz y buena olla para privilegiados, pero también un foco cultural muy activo en aquellos tiempos difíciles, como muestran algunos estudios recientes (Ascunce, 1999).

La colaboración profesional entre Mihura y Tono fue siempre incierta y es una muestra más de que entre los miembros de la también llamada «Otra Generación del 27» existió amistad, sí, pero no una fluida disposición al trabajo en común. Los celos, la desconfianza o, sencillamente, el afán protagonista de la mayoría de estos personajes no facilitó las cosas y no puede decirse que los trabajos en colaboración fueran abundantes ni duraderos.'En todo caso, el reencuentro de Mihura con Tono supuso el comienzo de un periodo de entendimiento, que finalizaría unos años más tarde, cuando las diferencias económicas y de criterio entre ambos provocaron la ruptura definitiva -profesional, no afectiva- tras el celebrado estreno de Ni pobre ni rico, sino todo lo contrario (1943). Tono, un autodidacta como su amigo, había tenido la ocasión de aprender mucho sobre ilustración gráfica durante sus estancias en Estados Unidos y Francia y su experiencia le valió ser nombrado director artístico de la revista mensual Vértice, la más ambiciosa empresa periodística de Falange, fundada en abril de 1937.También Miguel mantuvo allí una colaboración regular hasta finales de 1938; y en sus páginas vieron la luz algunas «falsas biografías» firmadas con el seudónimo que Tono y Mihura, Mihura y Tono, harían popular en esos años: Tomi-Mito.

Pero fue en el diario Unidad donde esa firma compartida dejaría más huella. Ambos humoristas se alternaron durante una temporada con una tira cómica: «La semana de Don Mario de la O», de Tono, y «La semana del Señor Caradepato», de Mihura, que durante la guerra firmó siempre como Lilo. Y fue en ese diario donde la firma Tomi-Mito inició la publica-

1. Resulta especialmente significativa la agresiva actitud que mostró en los años treinta Jardiel hacia Mihura, a quien acusó de plagio en público y en privado. Véase al respecto el relato de esta difícil relación en mi biografia de Mihura(Moreiro, 2004: 81-87). El autor de Tres sombreros de copa tampoco fue un ejemplo de ductilidad: su colaboración con Calvo Sotelo, primero, y Álvaro de Laiglesia después, concretada en sendas comedias -iViva lo imposible! (1939) y El caso de la mujer asesinadita (1946)-, terminó pronto y no se resolvió de manera cordial. 
ción, en abril de 1937, de una serie de breves estampas narrativas bajo el título genérico de «Siete meses y un día en Madrid», que supusieron el debut de Tono como autor literario. La serie, cuyo título aludía a la experiencia de Mihura en la capital sitiada, tuvo continuación entre los números 44 y 61 deLa Ametralladora (noviembre de 1937-marzo de 1938), bajo el rótulo en este caso de «Madrid comunista». Posteriormente, las veinticinco estampas verían la luz en forma de folleto con el título definitivo de María de la Hoz, tomado de una parodia de la famosa tonadilla «María de la $\mathrm{O}$ » publicada por Mihura en el número 42 de La Ametralladora y que bien puede considerarse como primer modelo de un estilo perfeccionado luego por Tono y que, años después, produciría las muy celebradas «alegres canciones») de La Codorniz.

Aunque no es este el lugar para entrar en un análisis detallado de la cuestión, parece claro que, en el trabajo compartido, Mihura, más experimentado como escritor, es el responsable de la adopción de un determinado punto de vista y del tono general de los textos; por su parte, Tono aporta la intuición, la capacidad inventiva -que en ocasiones no acertaba a controlar- y esa habilidad para la improvisación que constituyen sus principales virtudes y que llevaron a Gómez de la Serna a considerarlo como la encarnación del nuevo humorismo en un artículo publicado en La Estafeta Literaria en diciembre de 1956. Las discrepancias de carácter entre uno y otro (mucho más abierto y cordial Tono, más caprichoso y arbitrario su amigo) se manifiestan también en el terreno estilístico: Mihura tiene más dotes como creador, conoce el sentido de la medida y no suele dejarse llevar por excesos; Tono es menos comedido, más torrencial y lo mismo acumula ocurrencias o imágenes que repite y exprime los gags hasta dislocar el texto. En María de la Hoz, las diferencias que acabo de apuntar resultan evidentes.

La propaganda se consideró desde el principio una poderosa arma de guerra en la zona franquista; el decreto de unificación de 1937, permitió controlar toda la maquinaria puesta al servicio de la difusión de consignas (Pizarroso, 2005). A la copiosa cosecha propagandística oficial, hay que unir las contribuciones que, en número considerable, a través de la prensa o por medio de libros y folletos, hicieron quienes habían huido de zona republicana (Langa Nuño, 2000). En unos casos por convicción profunda, en otros con el ánimo de hacer méritos o, incluso, de borrar flaquezas pasadas ahora inconvenientes, una serie de periodistas e intelectuales aportan su grano de arena a la abundante bibliografía de combate. Entre 
esas aportaciones, están las de quienes relatan los horrores vividos en las ciudades sometidas a la «barbarie roja»; ni que decir tiene que la mayoría de los testimonios se refieren a Madrid.

Esos textos destacan por su violencia verbal y por la contundencia de sus juicios, como pone de manifiesto, por ejemplo, un libro publicado en Valladolid por el periodista Joaquín Romero-Marchent (Romero-Marchent, 1937) con el título de Soy un fugitivo. Este personaje, cuyo fervor tal vez se explique por la necesidad de hacer olvidar algunos detalles de su pasado, alude a Madrid como la ciudad secuestrada «por lo peorcito de cada casa», define a la España leal como «mal oliente, desgreñada, zafia y brutal», se emplea a fondo contra las mujeres republicanas («babeantes de lujuria social», dice) y considera que Margarita Nelken y la Pasionaria son «la síntesis de todas las malas hembras, de todas las malas madres que alimentaban las inclusas, de todas las arpías, de todas las rameras». Anticomunismo, antipatriotismo, degradación moral y corrupción política son las características que adornan a la sociedad republicana, de acuerdo con los dictados oficiales de la propaganda franquista; en cuanto al tono empleado por Romero-Marchent -conocido y contertulio ocasional de Miguel Mihura-, puede servir de referencia para el que ofrecen panfletos similares.

Pues bien, María de la Hoz representa una excepción. Sin duda, comparte con otras publicaciones toda una batería de lugares comunes para dibujar con sarcasmo al Madrid sitiado; y es, como tantos otros, un producto ocasional que contribuye, pese ala vocación abstinente de sus autores (más clara en el caso de Mihura que en el de Tono), a desacreditar los valores y las creencias de uno de los bandos en guerra y a poner en cuestión la talla moral e intelectual de los líderes republicanos; pero el punto de vista elegido por los humoristas introduce una ironía distanciadora de gran eficacia expresiva y confiere a sus páginas un cierto porte estético, ausente por completo en otros productos de aquella hora. Ni siquiera encontramos aquí el léxico característico de esas publicaciones, integrado por palabras como 〈barbarie», «hordas», «ratas», «energúmenos», «canalla», «sin Dios», «bárbaros», etc; el contenido resulta menos burdo y queda tamizado por los hallazgos formales, irregularmente repartidos por el texto. Su peculiaridad queda de manifiesto desde el párrafo inicial, que deja entrever el propósito que anima a Tono y Mihura en su empresa: «Al declararse la guerra en España, lo primero que hizo el Estado Mayor del Gobierno revolucionario fue reunirse en el café Colonial para tomar acuerdos y unas gambas». La incompatibilidad semántica de esa coordinación entre dos elementos heterogéneos tienen el valor de una tarjeta de visita, tanto en el plano estilístico como en el temático: los personajes 
adquieren, ya en esas líneas, naturaleza de títeres, y los autores hacen que se muevan en un ambiente propio de la farsa esperpéntica.

Ahora bien, ello no obsta para que María de la Hoz entre de lleno dentro de la literatura de combate, participe de la tosquedad de la propaganda nacionalista y merezca reflexiones como esta:

Leer textos propagandísticos publicados durante la guerra resulta penoso. Intentar adentrarse en los razonamientos que los orientan nos lleva a campos todavía más lamentables. Y el resultado, por obvio, apenas aporta algo significativo. Maria de la $\mathrm{Hoz}$ es un folleto que, una vez consultado, conviene olvidar. Hasta cierto punto, pues ese olvido nunca se debe extender a la evidencia de que los humoristas también se involucraron en la guerra. Con todas sus consecuencias, que fueron to desagradables que cabía esperar en un enfrentamiento fratricida donde apenas quedó margen para el respeto al contrario, la búsqueda de caminos de paz y la reconciliación (Ríos Carratalá, 2005b: 124)

Analizar brevemente este título es una decisión que, me parece, se justifica en razón de los límites que el profesor Ríos Carratalá señala al olvido (inevitable destino, por lo demás, para el folleto de Tono y Mihura); pero también porque constituye una muestra representativa -apenas tenida en cuenta por los estudiosos- del humor cultivado en España durante el franquismo inicial, cuando la propaganda era otra forma de ocupar líneas en el frente de guerra.

\section{Otra crónica de guerra}

El texto que nos ocupa apareció en el n 25 de la Novela del Sábado, una publicación semanal que nació en Sevilla el 28 de enero de 1939, de la mano de Falange y bajo la dirección de Joaquín Pérez Madrigal, con el expresivo subtítulo de «Genio y hombres de España», luego desaparecido; en ese primer número incluía la reedición de Marruecos. Diario de una bandera,de Francisco Franco. A partir del $n^{\circ} 16$, de 2 de septiembre del mismo año, pierde el tono agresivo con que hasta entonces había defendido los ideales del nuevo régimen y combina los textos propagandísticos con otros de entretenimiento; la edita desde entonces Ediciones Españolas S.A., empresa ubicada en el $n^{\circ} 40$ de la calle de Almagro de Madrid y recoge durante unas semanas ilustraciones firmadas por Tono. En enero de 1940 cambiaría de formato para incorporar contenidos más propios de una revista de variedades. Desapareció unos meses después (Naval, 2000).

María de la Hoz fue publicada el 4 de noviembre de 1939, en un folleto que llevaba como ilustración de cubierta la fotografía de una mi- 
liciana con fusil y pistola al cinto. Además del relato - que, ilustrado por los mismos autores, ocupaba 59 de las 128 páginas totales-, el $\mathrm{n}^{\circ} 25$ de la Novela del Sábado incluía un cuento de José María Salaverría («Un drama en el restaurante»), una semblanza de Ramiro Ledesma Ramos a cargo de Juan Aparicio, el artículo «La patria, el pan y la justicia» del propio Ledesma, un apunte sobre Zorrilla firmado por E. Ramírez Ángel, una reseña crítica de Nicolás González Ruiz a propósito de la novela de Mariano Tomás La niña de plata y oro, un perfil biobibliográfico de J. Ortiz de Pinedo sobre Fernando de Rojas y unas páginas misceláneas con noticias sobre la vida literaria, consultorio bibliográfico y filológico, crónicas sobre la vida universitaria, pasatiempos y anuncios. Esta somera descripción da idea del contenido diverso de una publicación peculiar, que trató de recuperar sin éxito exitosas fórmulas editoriales de los años treinta.

Las páginas de Maria de la Hoz están precedidas por un sucinto prólogo del influyente periodista bilbaíno Jacinto Miquelarena, buen amigo de Tono y Mihura desde los años donostiarras. Parece escrito de compromiso y nada dice acerca del contenido del relato; Miquelarena emplea un tono que trata de acomodarse al humor disparatado de los autores, a quienes presenta como descubridores del «cráneo cónico» y expertos en «conicefalismo».

Estamos ante un librito que carece de plan, compuesto como mero agregado de escritos, unidos por su referente (el Madrid republicano) y por el empleo de unos recursos humorísticos que constituyen el elemento vertebrador. Consta de veinticinco capítulos breves, de entre quince líneas y dos páginas, cuyos títulos remiten con frecuencia a los utilizados por Mihura en sus artículos de Gutiérrez: «Era un barco de oficinistas y la tinta se les terminó»», «Historia triste del batallón de «Las Infames»», «Aquellas vacas que se disfrazaron de milicianas...», etc.; otros, en cambio, anuncian el tono directamente beligerante de su contenido satírico, especialmente en las páginas finales, como es el caso de «Los últimos inventos para justificar la revolución» o «La gran carnavalada de la revolución». De las colaboraciones de Mihura en la citada revista madrileña proceden, con las oportunas adaptaciones, diversas estrategias discursivas distribuidas aquí y allá y no menos de tres capítulos completos.

El texto pasa revista en clave paródica, y en un tono que en ocasiones no rehuye las expresiones gruesas y hasta se complace en ciertas bromas de dudoso gusto, a los tópicos acuñados por la maquinaria propagandística del franquismo sobre la España republicana. Como advierte Ramoneda (2004: 45) el propósito distorsionador «no impide que se pongan de manifiesto los afanes de los autores por ridiculizar y presentar de forma grotesca una realidad dramática y conflictiva $[\ldots]$ y, sobre todo, el deseo 
de igualdad social y de poner fin a los abusos de las clases superiores y las aspiraciones sociales de los obreros, de los campesinos andaluces y de los marineros»».

El telón de fondo, el paisaje humano que pulula por estas páginas, deriva de la imagen simplista y caricaturesca que las derechas tenían de los rojos. Podemos leer, así, cómo los comunistas -tras ser adiestrados por los rusos, que prestan una ayuda tan absurdamente ineficaz que llevan hasta Valencia barcos cargados de naranjas- «habían robado tanto dinero y eran tan ricos, que usaban los automóviles una sola vez. Después de usados los tiraban, como se tiran las cerillas»; los revolucionarios son una partida de corruptos propensos a dejarse seducir por los anarquistas: « $\mathrm{Si}$ la gente conseguía comer algo era porque casi todos tenían algún miliciano que, metido en su tanque, iba por la noche a llevarles a su casa un kilo de arroz. Y con el arroz los madrileños conseguían hacer maravillas. Había quien con solo arroz hacía filetes con patatas y calamares en su tinta»; los principios revolucionarios se reducen a la lógica de los cuentos para niños: «Lo que más les sonaba a todos era eso del reparto de la tierra, y a cada momento decían que debía repartirse la tierra. - ¡La tierra para el que la trabaja!-, exclamaban a gritos los dependientes de las tiendas. Y, para empezar, decidieron repartirse el Retiro, que es tan grande, y las mujeres y los niños iban con cubos y con palas y cogían tierra y se la llevaban a casa»; y como niños presumen los milicianos de sus nuevas amistades: «Cuando llegaron los tanques rusos, todo el mundo quería tener un tanque o, por lo menos, dar una vuelta en un tanque. Los milicianos se los llevaban a Madrid en cuanto podían para darse el gustazo de ir al Café Colonial a tomar café y dejar el tanque a la puerta. Los antiguos abrecoches se hicieron abretanques y cobraban más propina que anteriormente».

Los autores aplican a la realidad el mismo punto de vista deformador que Mihura empleara en los escritos de su última etapa en Gutiérrez. El efecto es divertido y eso permite que la burla suavice un tanto el evidente propósito de presentar el Madrid asediado como una ciudad absurda, convertida casi en un escenario guiñolesco, donde los madrileños van a pasar la tarde al frente, como podrían hacerlo a una verbena (para ellos la guerra es una realidad disparatada, como lo es para el Estado Mayor, que, a la hora de comprar material bélico, encarga termos, peines, abrelatas, botellas de cervezas, cuerdas, etc.); se suben a los coches en el pescante, junto al cochero, y en los tranvías en la plataforma, al lado del conductor, para que nadie los tome por señoritos; o convierten las colas en una pasión que los entontece: "Ya las colas no se organizaban dentro de los establecimientos. La gente se citaba en el Hipódromo o en la Castellana y allí era donde se formaban grandes colas, compuestas por doscientas o trescientas 
personas. Cuando ya estaban hechas se ponían en marcha, y entonces las colas iban recorriendo las calles y buscando una buena tienda donde ponerse». En cuanto a los líderes políticos, son personajes inconsistentes que bordean el cretinismo, se toman sus obligaciones como un juego infantil y parecen haber perdido su naturaleza de seres humanos, al punto de que, mientras Azaña «estaba hecho un hombre muy mujer de su casa», la $\mathrm{Pa}-$ sionaria era, en realidad, «un señor de luto, con barba y bigote, que ganaba tres duros diarios por hacer el papel de La Pasionaria».

La Pasionaria fue uno de los blancos preferidos de la propaganda franquista y uno de los símbolos rojos más vilipendiados por sus voceros; probablemente, María de la Hoz es una alusión a esta figura, que concitó el furor misógino en un momento en que la relevancia pública de las mujeres republicanas lo alentó hasta la exasperación. Tono y Mihura participan, desde luego, de ese lugar común, pero sus palabras resultan menos virulentas que sarcásticas porque ambos están más interesados en dibujar una viñeta cómica que en subrayar la degradación de un personaje que llegó a encarnar todas las maldades de la anti-España. Valga como ejemplo el pasaje en que encontramos a la dirigente comunista arengando a los mineros, quienes, enfervorizados por el discurso, gritan: «iMas vale ser viudo de una héroa que marido de una cobarda!».

Las convicciones misóginas de los autores quedan de manifiesto con mayor claridad en los capítulos XIII, XIV y XV, protagonizados por el feroz batallón de «Las Infames»; pero la sátira no se ceba en la consabida imagen de la mujer anticristiana, antiespañola y antifemenina, sino que lleva el sello personal de Mihura -que ya había escrito textos con un propósito similar en Gutiérrez-, más interesado por trasladar su idea de que para las mujeres -sean estas pobres muchachas de servicio, vicetiples con aspiraciones $\mathrm{o}$, ahora, milicianas - la vida se reduce a buscar marido y a representar aplicadamente su papel de adorno social. «Las Infames» -cuarenta milicianas empleadas del matadero municipal- eran «muy guapas y muy bien formadas y representaban la gracia madrileña y el tronío ese. Todas iban derramando paquetes de sal y pimienta»; tras ellas iba otro batallón «compuesto por señoras gordas, que eran las madres, y que iban comiendo bocadillos de jamón artificial». Las infames entienden la guerra de una manera insólita, y su conducta en nada se distingue de la de las modistillas madrileñas retratadas con ironía por Mihura en distintos escritos de los años treinta: así, coquetean con los miembros del batallón «Los feroces dependientes de Ultramarinos» mientras los pajaritos cantan La Internacional y, a poco, se casan con ellos para, a continuación, engañarlos con el batallón de «Los Corsarios» y dar lugar a un final trágico, propio de folletín. 
Si me he detenido en este último episodio es porque me parece característico del tono general de María de la Hoz, donde los autores (y especialmente Mihura, a quien ha de atribuirse la mayor parte de la invención) hacen un ejercicio interesante por infrecuente: aplicar a una realidad dramática, que ven desde prejuicios ideológicos compartidos con otros escritores adeptos al incipiente régimen, un tratamiento estético en principio inconveniente, basado en los principios del humor inverosímil o absurdo que se había impuesto en los años anteriores a la guerra. El resultado -apreciable también en muchas páginas de La Ametralladora-es, cuando menos, desconcertante, y aconseja colocarlo en un aparte dentro de la literatura de urgencia y propaganda. A fin de cuentas, mientras otras publicaciones fueron solo una contribución interesada, una inversión de futuro, esta cuenta en su descargo con la excusa de haber tendido un puente entre el humor de los años treinta y el que, poco después, cristalizaría en La Codorniz.

\section{Final}

Como señala Ríos Carratalá (2005b:110), las publicaciones de los humoristas del 27 durante los años de la guerra no añaden nada a su gloria literaria: les fueron útiles porque evidenciaron su adhesión a los vencedores cuando ello fue imprescindible, pero después las olvidaron, no por exigencias de una inexistente evolución ideológica, sino porque una toma de partido tan descarada no se avenía con la imagen que cultivaron de sí mismos durante el resto de su vida. Son palabras que pueden aplicarse ajustadamente a Mihura, un hombre que procuró siempre vivir en su rincón para ver desde allí la vida con una displicencia inteligente; y algo parecido puede decirse de Tono, aunque su carácter más extravertido lo llevó a dejarse ver más, pero sin adoptar una postura ideológica comprometida.

Ni uno ni otro recordaron nunca María de la Hoz más que lo imprescindible para incluirla -y no siempre-en la relación de sus publicaciones. Cuando en 1962 aparecieron las incompletísimas OO.CC. de Miguel Mihura, el dramaturgo prefirió olvidarla. El texto no volvió a reproducirse hasta que Arturo Ramoneda lo recogió en el volumen recopilatorio Prosa y obra gráfica, ya citado, aparecido en 2004. En los casi setenta años que median entre esa fecha y la de la primera edición, María de la Hoz no ha merecido la atención de nadie, ni siquiera cuando, en los últimos años, aumentó el interés por la literatura de guerra.

Un volumen como este, dedicado a analizar manifestaciones diversas del humor durante el franquismo, no podía pasar por la alto unas páginas 
con las que dos de los grandes del pasado siglo pagaron su óbolo a los vencedores de una guerra, conscientes de contarse entre ellos. Constituyen una prueba de que, en efecto, también los humoristas fueron a la guerra y se decantaron por la España que mejor se avenía con sus creencias más genuinas, aprendidas en la escuela burguesa aunque fuera entre mohínes y protestas. 


\section{BIBLIOGRAFÍA}

Ascunce, José Ángel, San Sebastián, capital cultural (1936-1940), San Sebastián, 1999.

Díaz, Elvire, «Humour et politique: Gutiérrez (1927-1934) et l'actualité des années trente», Bulletin d'Histoire contemporaine de l'Espagne, 25 (1977), pp. 283-296.

LANGa Nuño, Concha, «Los civiles somos víctimas de la guerra y de la propaganda. El ejemplo de la guerra civil española (1936-1939)», Revista Latina de Comunicación Social, 32 (2000). http://www.ull. es/publicaciones/latina/aa2000kj1/y32ag/75langa.htm.

MARAÑA, Félix, «San Sebastián, centro cultural y editorial durante la guerra. La Ametralladora y otras publicaciones», en M. Tuñón de Lara (dir.),Comunicación., cultura y política durante la II República y la guerra civil, Bilbao, Universidad del País Vasco, 1990, vol. I, pp. 193-206

Minura, Miguel y Tono (Antonio de Lara), María de la Hoz, Madrid, La

Novela del Sábado, 1939. (Incluida en Mihura, Prosa y obra gráfica,

Madrid, Cátedra, 2004, pp. 903-947).

Moreiro, Julián, Mihura. Humor y melancolía, Madrid, Algaba, 2004.

Naval, Ma Ángeles, La novela de Vértice y la Novela del Sábado, Madrid, CSIC, 2000.

Pizarroso Quintero, Alejandro, «La guerra civil española, un hito en la historia de la propaganda», El Argonauta Español, 2 (2005). http:// argonauta.imageson.org/document62.html.

Ramoneda, Arturo, Int. a Miguel Mihura: Prosa y obra gráfica, Madrid, Cátedra, 2004, pp. 19-63.

Romero-Marchent, Joaquín, Soy un fugitivo (Historia de un evadido de Madrid), Valladolid, 1937.

Ríos Carratalá, Juan A., «La guerra de los humoristas», Quimera, 257 (2005a), pp.18-22.

- «Miguel Mihura también fue a la guerra, aunque poco» en Rafael Pérez Sierra, Felipe B. Pedraza Jiménez y Milagros Rodríguez Cáceres (eds.), Miguel Mihura cumple un siglo. Actas de las jornadas en homenaje al humorista y dramaturgo, Comunidad de Madrid, 2005b, pp. 99-115. 